\title{
Teaching Reading and Writing through a Web-Based Communicative Medium: Weblog
}

\author{
Jafar Askari Arani \\ Faculty member of Kashan University of Medical Sciences, English Department
}

\begin{abstract}
:
With the advent of push-button publishing in the field of ICT, in the shape of weblog, language teachers now have a new way to entice students to communicate through their reading and writing. Web blogging started fairly in 1990, and refers to websites that are continuously updated (Blood,2000). According to Richardson (2004) language teachers can subscribe to their students linguistic abilities especially in writing and readingThis paper discusses how weblogs develop writing, reading and communication skills. The positive and negative potential of weblog for language teacher is discussed, the use of weblogs in a writing class for non-native English speakers in the second year of university study is demonstrated and the feedback from these students is considered .
\end{abstract}

This quasi-experimental study was conducted on 40 non-native English speakers of upper-intermediate level. They were university students in two classes at the Kashan University of Medical Sciences. At the end of the course, but before they had received their final grades, the students were given two questionnaires (multiple-choice and explanatory) to assess the effectiveness of this assignment.

The vast majority of students preferred English writing the weblog to the more traditional ways. Most of them believed that weblog can improve English and a few of them said that they would definitely continue using wblog. The findings seem to confirm that despite generally having no prior experience of web design, most of the students enjoyed the assignment, believed that it was helping the improvement of their English and that it assisted them in producing good work. 
Blog assisted language learning (BALL) not only provides teachers with an exciting new way to approach communicative language learning, it also, despite facing challenges, gives the students a new reason to enjoy reading and writing.

Keywords: Blog Assisted language learning (BALL), Teaching English as a foreign language, Reading, Writing, I CT,

Weblog.

\section{Introduction:}

The scene of education is changing quickly and significantly. Educators are trying to keep up with new developments causing or resulting in the change. When confronted by pedagogical questions, they seek answers to the questions through various types of research and practice. A recent trend in the research and practice is the creation or employment of innovative approaches that respond to the need for an underlying pedagogical framework to support the use of information and communication technology (ICT) and the integration of ICT into the teaching and learning process. Journal Writing, now called weblog, as a medium in this field has been used in the language classroom as a tool to enhance learning (Boswood 1997).

This paper examines the definitions of 'weblog', and discusses how weblogs develop writing, reading and communication skills in the field of Blog Assisted Language Learning (BALL). The positive and negative potential of weblogs for language teachers is discussed, the use of weblogs in a writing class for non-native English speakers at Kashan University of Medical Sciences in the first year of university study is demonstrated, and feedback from these students is considered.

Weblogs have exploded in popularity in the last few years. While originally blogs were nothing more than frequently-updated HTML files, now blog software ("blogware") has made creating, hosting, and updating blogs even easier. As this new web genre emerges, we might begin to form a definition of it. The fact that "blog" is a contraction of "weblog" suggests that a blog (a) must be on the web and (b) must in some sense "log" something.

With the advent of push-button publishing, in the shape of the weblog, language teachers now have a new way to entice students to communicate through their reading and writing (Boswood 1997) .

The dynamic content of a weblog may sometimes resemble the 'Send to All' FW email, and its interactive nature, which often allows the reader to respond, also echoes the online discussion board. However, the weblog is a unique entity. It physically looks like a website rather than an email correspondence. Furthermore it is less intrusive than FW 
email because it exists in its own autonomous space online, rather than squatting in an inbox. Blogs are often aimed at a broader readership than the blogger's own friends and family because they communicate with the diverse blogging community as a whole(Barret 1999).

Weblogs also tend to have features which are not available on most regular web pages. The comments feature, for instance, that allows the reader to write onto the weblog either directly or following approval from the author. Some weblog companies also offer Email / SMS publishing which allows the blogger or a group of bloggers to post to the weblog directly using email or mobile phone messaging. A subscription feature is also available, which enables the blogger to automatically receive updates of his/her favorite weblogs whenever these are updated (Barrett 1999). This characteristic is also known as RSS, known as Rich Site Summary or Real Simple Syndication and its potential is huge. As Richardson (2004) points out under the heading "Subscribe to My Homework Page!" teachers can subscribe to their students' weblogs and will automatically be notified whenever changes are made to these weblogs.

In short, the weblog offers a free online publishing house for anyone who cares to write and for those who care to read it. Often described as a kind of public journal, the weblog is usually motivated solely by the need for self-expression, and often communicates something about the personality, or adopted persona, behind the blog, through the style of writing and the choice of topics. However, others might argue that a weblog is not really about the individual but the collective, the network; it is simply an elaborate list of links to other sites. For this reason, Blood (2000) states the need for a clear distinction between the filter style weblog which relies on links and the journal style blog which is more personal and reflective. Similarly, Hasting (2003) draws attention to the duplicitous nature of the weblog which can be, "a frequently posted list of interesting web sites, or a personal diary of events and thoughts, or a combination of the two (among many things)" (p. 1).

\section{Discussion:}

Writing group blogs can help make the writing process transparent not only to the students, but to instructors as well. Instructors can see what writing projects evolve, and follow along as the group makes collective decisions. An instructor could be a fellow author of the group blog, and intervene or redirect the process with posts or through comments. The latter may be preferable because it is less intrusive, and then the instructor can model effective feedback with comments.

Teaching writing for an audience is a challenge especially when teaching to students who have never written anything in English except assignments for their teacher. These students may not only have difficulty adjusting their writing to fit the reader, but may have trouble getting started because, aside from the final grade, what they write does not 
mean anything to them because it does not need to mean anything to anyone else. However when writing for a weblog, "the [online] audience is not only anticipated but expected, and thus influences and structures the very manner in which the writer articulates, composes, and distributes the self-document" (Kitzmann, 2003, p. 1). Kitzmann describes how the potential of online celebrity provides a powerful motivating force for the writer, playfully re-appropriating Descartes' maxim to describe the existential stimulus of the compulsive blogger, "I write about myself, therefore I am" ( $p$. $6)$.

For the language teacher the weblog is a timely arrival which can fulfill many of the needs identified for the effective teaching of writing. The weblog provides a genuine audience, is authentically communicative, process driven, peer reviewed, provides a disinhibiting context and offers a completely new form with un-chartered creative potential.

Opp-Beckmann (1999) describes the benefits of having an audience that is multicultural, responsive and networked. She celebrates how the developing technology of new media also enables students to become both the author and the audience, and can even provide communication between the different audiences (p.80). Because weblogs can offer twoway communication through group blogs and comments, there is literally a new dimension to this type of composition.

Indeed, continually updating a weblog, like regularly writing in a journal, may help writing students to appreciate that writing is an ongoing process, but with the added bonus of an instant and interactive audience. This advantage is described by Kennedy (2003) he describes how weblogs "combine the best elements of portfolio-driven courses where student work is collected, edited, and assessed, with the immediacy of publishing for a virtual audience" (p.4).

Furthermore, the audience brings its opinions, advice and criticism which as Stiler (2003) explains may "enhance the development of student reflectivity" (p. 2).. Welch (2003) claims that those who report the news now have, "something approaching real peer review, in all its brutality. If they truly value the scientific method, they should rejoice. Blogs can bring a collective intelligence to bear on a question" (p. 7). Likewise, Levey (in Glen, 2003) explains that blogging "has some of the best aspects of peer review built into it." And he goes on to explain how this aspect contributes positively to the quality of academic research: "Scholars' entries are instantly monitored and responded to by others as well-informed as they are" (p. 2).

In addition to providing a critical audience, another advantage that the weblog provides is the ability to communicate without the inhibitions and preconceptions that accompany most face-to-face interactions. Writing weblog is less formal and less threatening, thus students can write without self-consciousness or inhibition ( Roed 2003). She investigates this factor in her article, and explains how,

People behave differently when communicating online compared to a faceto-face situation. Research has shown that when communicating online, people show fewer inhibitions, display less social anxiety, and reduce their public self-awareness" (p.155). 
Roed also describes how the, often false, notion of anonymity that people have when communicating via the computer can be a major advantage for the language learner because it cuts down on anxiety and helps develop confidence. She explains that the term "disinhibition" has been coined to identify this factor. Disinhibition has been described by Johnson (1998) as "any behavior that is characterized by an apparent reduction in concerns for self preservation and the judgments of others" (Johnson in Roed, p.44). Roed (1998) also looks at how this phenomena affects the class as a whole, and observes that, "The group dynamics of the classroom are altered once the classroom becomes virtual" (p.157).

Udell (2001) reports that the weblog phenomenon has "emerged as a genuinely new literary / journalistic form" (in Stiler, 2003, p.4). In That different place: Documenting the self within online environments, Kitzmann (2003) confirms Walter Benjamin's belief that "technology has within it a 'nature' that comes from its own form" (p.10). Kitzmann suggests that new technology creates new concepts of communication, and concludes that blogging may be "constructing new forms and practices of both public and private space that have roots not only in culture but in the 'nature' of the technology itself" (p.10). The technology of blogging can provide dynamic content, connect multiple authors, facilitate an interactive relationship with an infinite and unknowable audience, allow the adoption of multiple personas, and incorporate multimedia. So it seems logical that the writer who uses the weblog and more pertinently the reader who seeks it out, will develop certain expectations and 'needs' that may not have existed in previous modes of communication. In this context, weblogging almost seems like an upgrade of writing but like most upgrades is a mixed blessing.

In addition to promoting extensive writing skills, it could also be argued that blogs help to develop reading skills through both content and form. For the L2 language learner, a wide choice of readily available L2 content covering a myriad range of current topics is available for free online. This material is also an invaluable source of authentic and communicative language in use. As Chun (1998) observes "For language learners in particular, computer networks and electronic mail provide students with opportunities for authentic communication with native speakers of the target language" (p. 57).

Another serendipitous advantage of blogging for the student is that the weblog reader, like the web surfer, develops effective lateral skimming and scanning skills through It might also be argued that writing blogs helps the students to read blogs and vice versa because through writing, the writer becomes more aware of the notion of audience; and through reading, s/he becomes more familiar with the corresponding idea of purpose The new Internet technology Weblogs is redefining the way students and teachers use the Internet, turning them from mere readers into writers to the Web as well, and making it easier to filter and track the ever-growing number of resources coming online each day.. regular use of this medium. These are skills which can then be used outside of the blogsphere and in the world of study.

The distinction between the reader and the writer is further blurred through the communicative nature of the weblog and the ease of online publishing (Lindemann 2001). Many weblog hosts now feature a constantly updated list of the most recently 'published' 
blogs in continual rotation. This means that the weblog reader can also skim through these 'racks' of blogs at random, like browsing through magazines in a library rather than searching for a particular book. The most active bloggers are most often seen in these racks and are therefore more likely to have the most frequently read blogs. This could be a powerful motivating factor for the blog writer to write regularly in order to develop a readership.

A further, more questionable, 'advantage' of using weblogs as reading material is that they expose the reader to fallible resources and diverse viewpoints, which may indirectly assist the student in developing critical thinking skills, although a more likely and unfortunate outcome is that some readers may be duped by inaccurate detail, false claims and questionable agendas (Boswood 1997).

Like any other medium, the weblog has its shortcomings and these will no doubt generate a great deal of debate as blogging becomes more ubiquitous in academia. It could be argued that not only does the weblog expose the students to some questionable readings, but that the format itself may have a detrimental effect on reading, writing and confidence (Hammesly 2003).

Wrede (2003) explains that just as weblog authors are not usually professional writers, weblog readers are not generally professional readers either. He warns that "this reading can't compensate for the weak writing skills of authors and potentially could be characterized as a kind of ...seeing what one wants to see, (selective perception)" (p. 5). There is a danger that the reading skills that are developed from scrolling the computer screen lead to an accelerated but superficial, and often inaccurate, understanding of the content.

Wrede (2003) also voices concerns about some of the disadvantages to writing skills that may be developed from activities such as blogging, suggesting that "technology can backfire if it takes too much control over representation" (p.5). This appears to echo the concerns of those who believe that technological communication advances such as instant messaging and mobile phone SMS-ing are also having a negative affect on literacy. There have been many cases of students using phrases like BTW (by the way) cuz (because) and $U$ (you) in submitted written work, and there was a well documented case of a student in Scotland who wrote her entire essay in SMS (Hammersly, 2003).

In addition to the possible disadvantages related to reading and writing, there are other risks linked to the public nature of weblogging. Students who post their work and ideas in the pubic sphere may receive some criticism which could be unproductive, hurtful or even offensive. If necessary, the students can block comments on their blog pending approval from the author. They also need to ensure that their own comments on other's blogs do not unwittingly cause offence.

\section{Weblogs in an L2 Writing Class}

The Assignment Prompt 
In order to get the students blogging, I started out by designing an assignment with one eye on the syllabus and the other on the 'blogsphere' to come up with the topics of news, views and reviews. I wanted the students to respond to an item in the news; articulate their opinions about an issue of their choosing; and critique a film and a book. I chose these topics because they were 'authentic'; that is they commonly appear on weblogs, and also because of several communication needs that needed to be addressed in the course. In order to have sufficient time to develop, the weblog was introduced at the beginning of the course and collected at the end. There were also a couple of posting deadlines to ensure that the students had started posting their blogs.

\section{Assessment}

The weblogs were assessed using a portfolio which contained printouts from the weblog plus a collection of the comments that each student had made on other people's blogs. I provided deadlines to post and a much later deadline for the final portfolio. This was for two reasons: firstly to check that blogs were posted throughout the course, ensuring that there were enough blogs for the students to read; secondly to encourage process writing because it is easy for the blogger to go back and edit the grammar or content.

At the end of the course, but before they had received their final grades for the weblog portfolio, my students were given a survey to assess the effectiveness of this assignment. These students are all non-native English speakers of intermediate to upper-intermediate level. Forty students were surveyed from two classes, twenty from each class. The following chart [Figure 1.] collates the first part of this survey which consisted of simple 'yes', 'not sure', or 'no' responses.

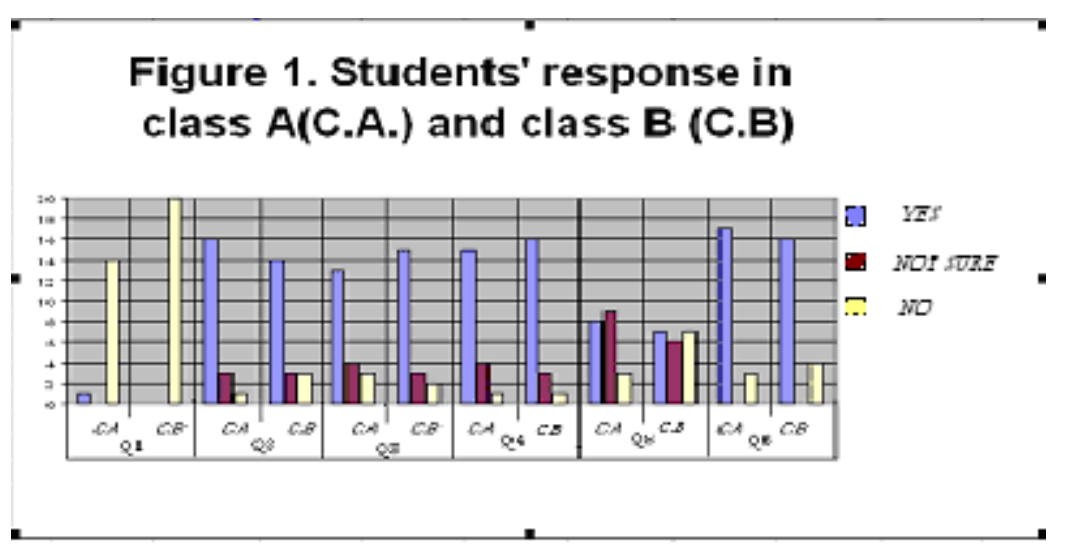

Q1: Have you ever designed your own webpage previously? 
Q2: Do you prefer writing the weblog to other ways of learning writing?

Q3: Do you prefer to choose your own topic?

Q4: Do you believe that an weblog can help improve English?

Q5: Will you continue to use the weblog?

Q6: Have you told others about the weblog?

From these results it is possible to deduce the following points:

- One student in both classes had designed a web page before.

- Approximately three fourth of the class preferred writing the weblog to the more traditional written journal

- Generally most students would rather choose their own topics

- Most students believed that the weblog can improve English; seven disagreed

- fifteen students said that they would definitely continue using the weblog; fifteen said they definitely would not, and ten were unsure.

- Thirty three students told somebody else about the weblog.

These findings seem to confirm that despite generally having no prior experience of web design, most of the students enjoyed the assignment, believed that it was helping the improvement of their English and that it assisted them in producing good work.

To respond comprehensively to all of the students' suggestions on the latter part of the questionnaire would take more time and space than we have here. Therefore samples of the most common and the most notable responses are discussed in this section. Obviously because all of the feedback is not included here, this report is not truly representative; however, it does contain an accurate reflection of the weblog experience.

In answer to the question, "Apart from this course, what else do you think you could use a weblog for?" One student mentioned that it could be an online diary or a place to post her pictures, drawings and paintings, while another mentioned that it could be a place to establish his writing on the web. Another respondent supported the notion of using the weblog for peer review, suggesting that the weblog is a good place to "take experience from" his friends' writing.

When asked, "Who did you tell about your weblog?" the most common responses were friends (21) and family (10), others said they had told their high school English teacher. I am convinced that many more people read the students' writing as a result of it being posted online. I also think that this encouraged the writers to take more care over what they produced. 
I also asked the question, "What was the most memorable thing that you read on other students' blogs?" This was in order to discover what types of writing work well on the blog and how I might best adapt the writing prompt next semester.

When asked, "What did you like the most about the weblog assignment?" One notable response was that the freedom of choosing topics helped to express and reflect personality and personal views. A couple of students highlighted how they appreciated the process approach of the assignment, one stating that she liked, "being able to fix it as much as I could and getting feedback from people." Another commented that "I was

able to take the time I needed and come up with ideas and great thoughts. I was able to go back and edit some mistakes I made." Similarly peer review was mentioned by one student who observed that the weblogs "improve our ability when we see the others' work." Other students said they enjoyed the "fun" novelty of the assignment which "didn't feel like writing essay." They also enjoyed the communicative aspect, and the fact that the blog was their own creative endeavor.

Dislikes mainly focused on technical problems. Most of the students wisely wrote their posts in Word so that they could check the spelling and grammar and save a back up; however, when they pasted from Word to the weblog the formatting would often be changed by the transition. Many found themselves with an unwanted white background and font sizes that they could not change. This tainted some of the students' pride in their blogs - when their babies turned ugly they stopped loving them. Some of those that decided to post their blogs directly to the site were faced with an even more harrowing prospect, vividly described by this student: "Once at midnight, I was on my weblog account typing my news, and as soon as I was done I clicked on save and BOOM it was all erased because I was 'inactive' for too long!"

A couple of the negative comments that were written about the weblog could actually be construed as positive points. One student unwittingly vindicated the process approach of extensive writing when he complained, "I had to do the work 3 times, 1st do it, 2nd post it, 3rd polish it." Another brought in the effect of audience on composition when he complained that "I have to write really good topics cause everyone will read my work." Also some complained that the pre-requisites to the adaptation of weblog into the classroom are ample ICT infrastructure knowledge and techniques .

When I asked the students how I could improve this assignment, I received some very constructive feedback which I will use as the foundation for the next draft of this assignment. A couple of students suggested smaller topics rather than the 'big' book and film reviews, and many asked for more freedom of choice of topics for weblog posts.

\section{Conclusion:}

In conclusion, the author is confident that as long as weblog providers continue to behave like email providers, and offer free and easy blogging services, the use of weblogs will continue to grow apace. There is every indication that weblogs will become more common than home pages and second only to email in online communication. As language teachers, if we are to equip our students with the ability to communicate in the online age we cannot afford to ignore blogging, or neglect the opportunities that this new 
medium offers. Like the student portfolio before it, the weblog faces challenges with practicality and security, but ultimately provides an alternative way to teach and assess authentic writing and reading skills. Blog Assisted Language Learning not only provides teachers with an exciting new way to approach communicative language learning, it also gives the students a new reason to enjoy reading and writing! The paper concludes that blogging has the potential to be a transformational technology for teaching and learning writing and reading, and universities ought to give strong consideration to the setting up blog facilities within their learning management system .

\section{References:}

Barrett, C. (1999). Camworld: rants, more about weblogs. Retrieved December 4, 2003, from http://www.camworld.com/journal/rants/99/05/11.html

Boswood, T. (Ed.) (1997). New ways of using computers in language teaching. Alexandria, VA: TESOL.

Blood, R. (2000). Weblogs: A history and perspective. Rebecca's pocket. Retrieved December 1, 2003, from http://www.rebeccablood.net/essays/weblog_history.html

Chun, D. (1998). Using CACD to facilitate interactive competence. In J. Swaffer, S. Romano, P. Markley \& K. Arens (Ed.), Language learning online (pp. 57-80). Austin: Labyrinth.

Glen, D. (2003, June 6) Scholars who blog. The Chronicle of Higher Education.

Retrieved December 1 2003, from http://chronicle.com/prm/weekly/v49/i39/39a01401.htm

Hammersly, B. (2003, May 15) If they won't write, get them to text. TEFL News, The Guardian. Retrieved December 18, 2003, from http://education.guardian.co.uk/tefl/story/0,5500,956003,00.html

Hastings, P. B. (2003). Histories of the weblog. Blogging across the curriculum. Retrieved December 1, 2003, from http://mywebspace.quinnipiac.edu/ PHastings/history.html

Kennedy, K. (2003). Writing with weblogs. Tech learning. Retrieved December 1, 2003, from

http://www.techlearning.com/db_area/archives/TL/2003/02/blogs.html

Kitzmann, A. (2003). That different place: Documenting the self within online environments. Biography, 26,(1), 48-65, 241.

Lindemann, E. (2001). A rhetoric for writing teachers $\left(4^{\text {th }}\right.$ ed). New York: Oxford University Press.

Opp-Beckmann, L. (1999). Classroom practice: Authentic audience on the internet. In J. Egbert \& E. Hanson-Smith CALL Environments (pp. 79-95). Alexandria, VA: TESOL. 
Richardson, W. (2004) Blogging and RSS - The "What's It?" and "How To" of Powerful New Web Tools for Educators. Retrieved March 10, 2004 from http://www.infotoday.com/MMSchools/jan04/richardson.shtml

Roed, J. (2003). Language learner behaviour in a virtual environment. Computer Assisted Language Learning, 16 (2-3)155-172.

Stiler, G. (2003). Blogging and blogspots: An alternative format for encouraging reflective practice among preservice teachers.

Wrede, O. (2003). Weblogs and discourse: Weblogs as transformational technology for higher education and academic research. Blogtalk conference paper -

Vienna,Education,123 (4), 789. May $23^{\text {rd }}$. Retrieved December 1, 2003, from http://weblogs.design.fh-aachen.de/owrede/publikationen/weblogs_and_discourse 